Katarína ŠTAFFENOVÁ ${ }^{1}$, Miroslav RAKYTA ${ }^{2}$
Supervisor: Miroslav RAKYTA ${ }^{2}$
DOI: https://doi.org/10.53052/9788366249844.19

\title{
SKANOWANIE LASEROWE 3D JAKO NARZĘDZIE INŻYNIERII ODWROTNEJ
}

Streszczenie: W artykule opisano proces inżynierii odwrotnej z wykorzystaniem technologii skanowania laserowego 3D. Poszczególne części artykułu zawierają informacje dotyczące inżynierii odwrotnej i skanowania laserowego 3D. Ponadto $\mathrm{w}$ artykule opisano proces inżynierii odwrotnej. Zawiera informacje o tym, jak wykorzystać technologie Przemysłu 4.0 do usprawnienia procesów digitalizacji.

Słowa kluczowe: Słowa kluczowe: skanowanie laserowe 3D, inżynieria odwrotna, modelowanie 3D

\section{D LASER SCANNING AS TOLL OF REVERSE ENGINEERING}

Summary: This paper describes the process of reverse engineering using 3D laser scanning technology Subsequent paper parts write up information on reverse engineering and 3D laser scanning. Next, the paper describes the process of reverse engineering. It provides information on how to use technologies from the Industry 4.0 to improve digitization processes.

Keywords: 3D laser scanning, reverse engineering, 3D modelling

\section{Introduction}

Recently, digitization has come to the forefront of the global pandemic. The most popular, among currently in use, are methods and tools based on visualization [1]. Companies approach to speed up the digitization process and began to use the new technologies offered by the Industry 4.0 concept. Such technology is also 3D laser scanning, operating in digitization for more than ten years. Over the years, this

\footnotetext{
${ }^{1}$ Ing., Department of Industrial Engineering, Faculty of Mechanical Engineering, University of Žilina, Univerzitná 1, 01026 Žilina, Slovak Republic, katarina.staffenova@fstroj.uniza.sk 2 doc. Ing., PhD., Department of Industrial Engineering, Faculty of Mechanical Engineering, University of Žilina, Univerzitná 1, 01026 Žilina, Slovak Republic, miroslav.rakyta@fstroj.uniza.sk
} 
technology has evolved and achieved high quality on the one hand on hardware and software side and the other hand on the usable side. Now it is a technology that has begun used in various ways and kinds of digitization. Reverse engineering has supported the potential for using 3D laser scanning for initial data. This technology has streamlined, accelerated, and increased the quality of the final drawing documentation as the final product of this process [2].

\section{Reverse Engineering}

Reverse engineering is one of the progressive technologies of production systems. It represents a technological process by which it is possible to create a CAD model or drawing documentation from an existing product according to specific customer requirements. It finds application in the creation of drawings of spare parts, the relevant technical documentation of which is either destroyed, incomplete or has never been created. Also when creating a shape-complex hand-shaped model from modeling clay or other prototype components. The data obtained in this way can be used in the production of components with a small number in batches on a $3 \mathrm{D}$ printer. Use of reverse engineering [3]:

- Creation of drawing documentation of prototype components.

- Shortening the product development and innovation cycle.

- Modernization of the production process.

- Design of new components adapted to existing components.

- $\quad$ Updating of drawing documentation of molds.

Digitization, as the main activity in the reverse engineering process for the field of mechanical engineering, and the collection of input data from a real object is possible in several ways such as manual measurement, semi-automatic touch probe measurement, laser surface scanning, optical 3D surface scanning or CT scanning.

Currently, the most used method of digitization for the needs of reverse engineering is laser scanning of the surface using a 3D laser scanner. Thanks to powerful technologies and a proven methodology for 3D measurement and 3D digitization, we can transfer complex shaped objects from the real world to digital form. Virtual 3D models are characterized by high accuracy, which is a prerequisite for their effective use in CAD systems. We digitize real models from the level of polygonal mesh (mesh), mathematically described objects (surfaces, holes, bevels) to editable models in CAD systems, all using combined contact measurement and scanning techniques and advanced reverse engineering methods [4].

\section{3D laser scanning}

Laser scanning, mainly 3D, is one of reverse engineering technologies representing modern access to digitization spatial information about the subject that can be used for 3D product and manufacturing systems, focusing the actual implementation of objects (industrial, artistic, and historical), focusing hard accessible and dangerous premises, animation and creation of $3 \mathrm{D}$ and simulation models. Figure 1 shows 
a customized methodology (sequence of steps) of 3D scanning verified in a specific company. A description of the individual corks can be found in Figure 1. We divide the digitization process according to the following steps:
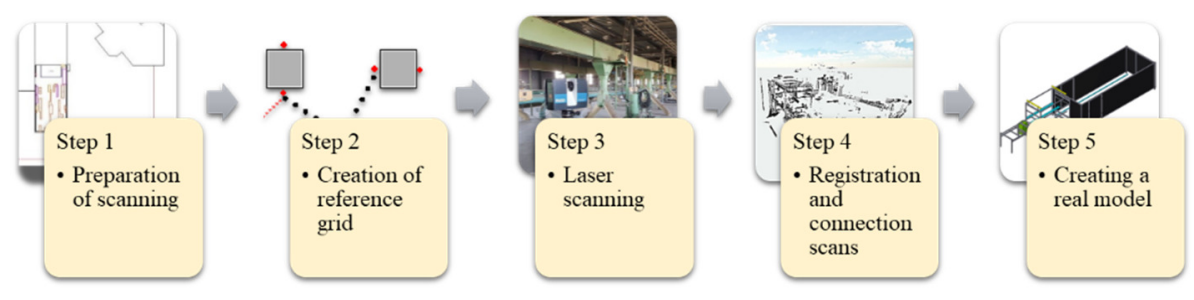

Figure 1. 3D laser scanning process (Source: own processing)

Step 1 represents the preparation of scanning - The technology described represents a high dimensional accuracy of 3D models up to $3 \mathrm{~mm}$. However, we consider it sufficient accuracy of $2-5 \mathrm{~cm}$. Subsequently, this accuracy affects scanning quality. At the beginning of each project, it is necessary to agree on all the conditions under which the models will be created or how they will be used in the future. For example, the model can be useful for reorganising or planning production, constructing object libraries, or analysing static structures. Each method has different criteria for scanning an object, scanner settings and subsequent model creation.

Step 2 represents the creation of a reference grid - Creating a 3D model depends on the scan of production halls. Before this step, reference points must be placed in the entire hall to create the reference grid in the enterprise. Each reference point is placed in a specific location and has its own coordinates and mark. This formation of the reference grid is later used when joining the scan and specifies the future virtual model. In the future, the enterprise can use the reference grid for the accurate location of production facilities, conveyors, transport systems, etc., which have been created in a 3D model. When placing the reference points, it is important to deploy these points so that they are insufficient quantity (minimum three) necessary for the exact location of the scanner in space. It is important to see at least four reference points whose distance is less than fifteen meters from the scanner from one scanning position. The reference points are dependent on the size of the hall and the degree of model detail. For example, in the hall with dimensions of $300 \times 100 \mathrm{~m}$ with two floors (together $60000 \mathrm{~m} 2$ ), there was a reference grid of the $12 \mathrm{~m} \times 8 \mathrm{~m}$ dimensions. Eight hundred reference points were used in the reference grid of such a dimension.

Step 3 represents laser scanning - The start of the coordinate system is in the centre of the scanning mirror in the device. The software can automatically recalculate the transformation matrix that all reference points have an absolute coordinate system. The core of the entire system is a built-in operating system that ensures collection, storing all data, scanning and easy data transfer to the external computer. This technology allows efficient, fast and accurate scanning of the entire production hall. Scanning is not only about a black and white photo but also about the coloured representation of truly measured spatial points, scans [5]. 
Step 4 represents registration and connection scans - Each scan point has 5 values: reflexion, $\mathrm{X}, \mathrm{Y}, \mathrm{Z}$ and distance from the scanner. After the scanning of the entire hall, it is important to connect the scans. This process creates a panoramic image and each point shows one coordinate in the hall. For the interconnection of scans, for their overview and navigation in the scanned hall, to measure distance and object dimensions and FARO Scene Software for scanners from FARO is used to export points to CAD system. FARO Scene is a graphical representation of visual perception, used as a basis for comparing reference points against which other objects can be evaluated. The goal of registration is the location of individual scans to a predetermined coordinate system as well as their link and insertion into a fixed single coordinate system. A correctly registered (registration of scans consists in their interconnection) scan is uniformly located at the level of the " $\mathrm{z}$ " axis with other scans and with the correct link to other scans.

Step 5 represents export data from graphic presentation to CAD system - Usually the data is exported to a CAD system: AutoCad, MicroStation, Intergraph, CATIA, etc. Using 3D scans, a new medium is created that represents a true reflection of reality. This medium is redrawn into a CAD drawing that represents reality. This drawing is divided into layers according to the character of the drawn object and is dimensional. To reduce modelling time, various libraries of parametric objects such as TriCAD are used. This library consists of a large catalogue of 3D objects, such as pipes, ventilation systems, electrical wiring, various steel structures, conveyors, various transport systems, etc.

\section{Process of reverse engineering used 3D laser scanning}

The reverse engineering process begins with selecting a tangible object for which it is necessary to prepare technical documentation. The object can be a component, assembly, machine or building, ventilation, pipe system, etc. For the needs of the research, an assembly was chosen, which consists of six components. This assembly serves as an intermediate piece for the pipe system in an industrial plant. The first step is to disassemble the assembly from the entire system and store the assembly in the space where the 3D laser scanning will be performed. This is followed by the creation of a reference grid around the assembly. The reference grid consists of the arrangement of the reference points. In this case, these are reference bodies - spheres. The reference spheres were chosen because of their shape. From each scanner position, the sphere has the same shape, making it an ideal reference body. After creating the reference grid, which means after placing the reference bodies, a 3D laser scan follows. The scanner positions are selected according to the need to focus the cloud from the object and according to the rules of the reference grid. The rule of the reference grid is the possibility to link scans during registration. We must see at least three reference bodies from the scanner position [6].

After scanning and transferring the data to the FARO Scene software, the scans are registered. All reference bodies are marked in each scan. After the overall registration, a $3 \mathrm{D}$ cloud of points of a real object is created. (Figure 2) 

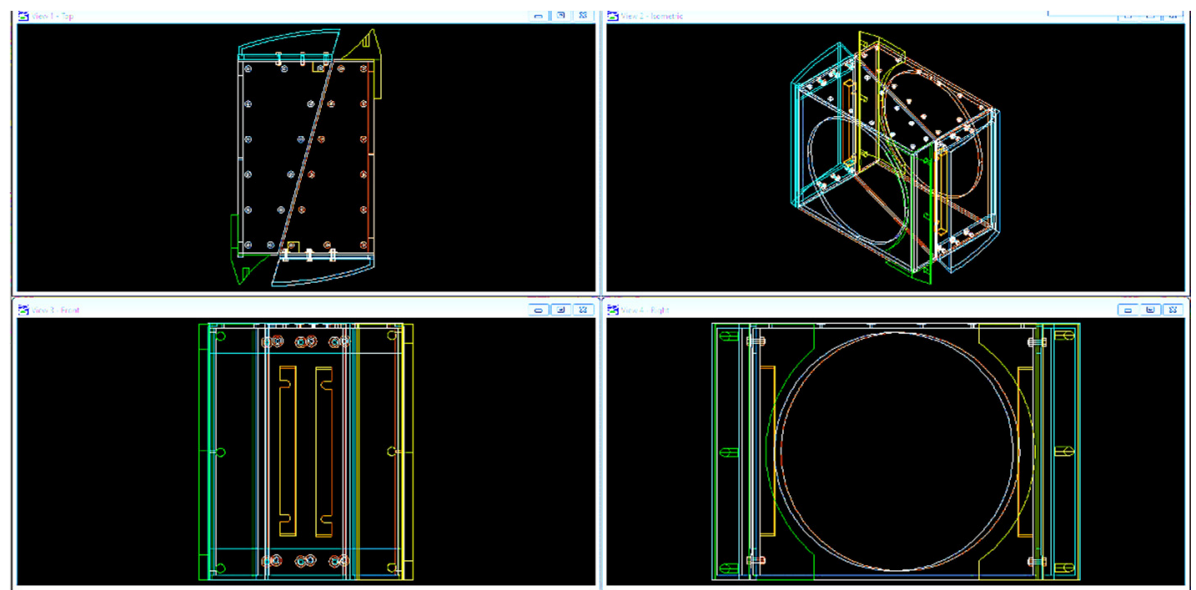

Figure 2. 3D cloud of points in software FARO Scene (Source: own processing)

The next step is to create a 3D model in the MicroStation V8 software environment. The point cloud is exported from the FARO scene software to the graphics software. In graphics software, a 3D model is created according to a real object, in accurate scale, and in an actual position relative to the zero point. This $3 \mathrm{D}$ model is measurable and dimensional and can be seen in Figure 3 in the MicroStation V8 environment. This graphics software offers modeling in all six views of the solid. Primarily four are used, from the top, front, right and isometric [7,8].

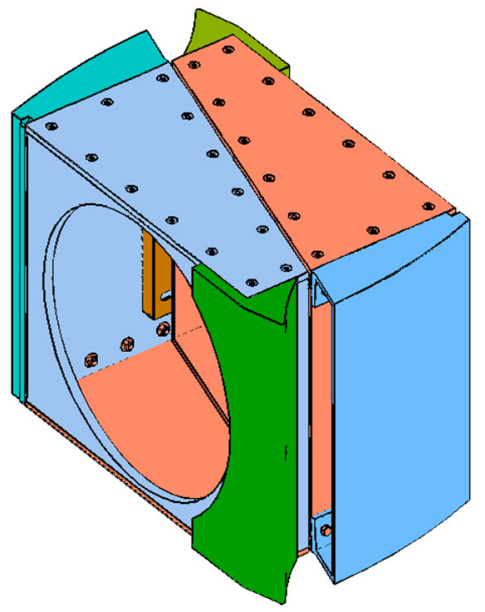

Figure 3. 3D model in MicroStation V8 enviroment (Source: own processing)

The primary output from MicroStation V8 software is in DWG format. Undoubtedly, it is possible to export the model to 3D PDF (Figure 4) or to DGN format, which is the primary documentation format for software from AutoDesk, such as AutoCAD or Inventor. 


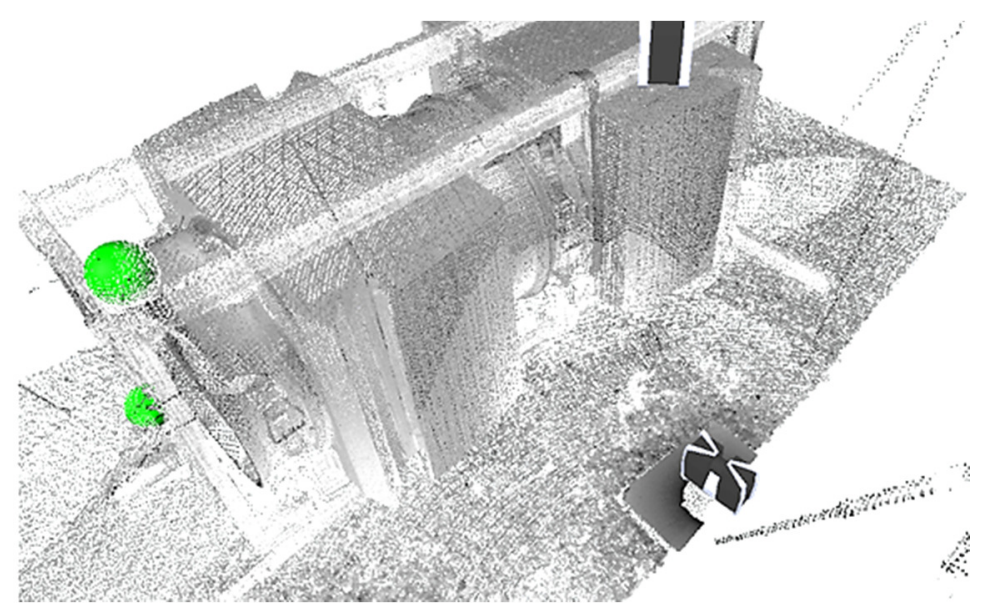

Figure 4. 3D model of assembly in 3D PDF format (Source: own processing)

Undoubtedly, we need to check the accuracy of the data before we complete the reverse engineering process. The FARO scene software will look at this option. It is possible to export the created 3D model using VRML format to this software. The exported model can be placed in a point cloud and visually inspected for deviations and inaccuracies that arise between the dimensions of the actual object and the model. When creating the technical documentation, the variance should not exceed $1 \mathrm{~mm}$. Figure 5 shows the exported model to a point cloud. In this environment, it is possible to move the entire cloud and create control from all model sides. We can also focus these deviations using a set of measuring tools in the software.

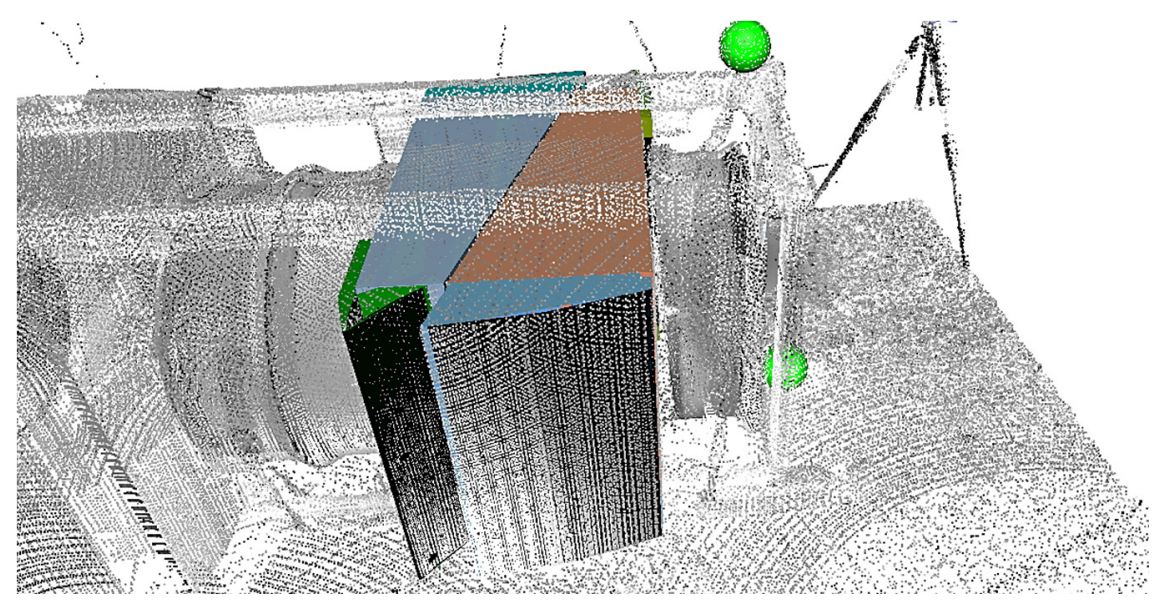

Figure 5. 3D model embedded in a point cloud (Source: own processing)

If the model passes the inspection, the final output and the final step of the reverse engineering process is drawing documentation. Drawing documentation, of course as part of the technical documentation, is used in a 2D drawing. This 2D drawing can be made in MicroStation V8 simply by exporting the visible and hidden edges in every view the creator needs to create a $2 \mathrm{D}$ drawing. The drawing is created in HLN format, 
which is a 2D drawing format, but other software can not process it efficiently, which means that after creating a 2D drawing, it must be exported to DGN format to work flexibly for further use such as construction. Or the actual production of a new piece according to this technical documentation. This drawing represents a part on an accurate scale and is fully dimensional for the needs of accurate dimensions of the selected object.

\section{Conclusion}

Data collection, use, and evaluation is the most critical element of the Industry 4.0 concept. The first step to creating a digital factory is to create a statically oriented graphic model of the entire production plant. Real data collection is essential for creating such a model. 3D laser scanning, as a progressive technology, offers a fast, reliable, and affordable way to digitize real objects. For buildings without technical documentation, it is advisable to use the reverse engineering process.

From a practical point of view, 3D laser scanning is currently a clear choice for collecting input data for the reverse engineering process. Using laser scanning, we have $3 \mathrm{D}$ cloud points on an accurate scale. According to this cloud, we can create a 3D model and then create technical drawing documentation. Software for working with cloud points offers the possibility of various control of dimensions and deviations of the model from the actual state.

These models can be used in the following steps to implement a digital factory. 3D models have a broad portfolio of usability. When creating a 3D model of the entire production hall, it is possible to solve design, layout solutions, optimization, etc. Another possibility is using models for simulation models for changes and process improvements in a manufacturing company. One of the other progressive approaches is to use $3 \mathrm{D}$ models for marketing purposes, whether it is gaining new customers, retaining regular customers, or addressing potential investors.

\section{ACKNOWLEDGMENT}

This work was supported by the Slovak Research and Development Agency under the contract No. APVV-19-0305.

\section{REFERENCES}

1. FURDYGIEL P., PLINTA D.: Production process improvement system. Wydawnictwo Naukowe Akademii Techniczno-Humanistycznej w BielskuBiałej. Bielsko-Biała 2020.

2. FUSKO M., GABAJOVÁ G., FURMANNOVÁ B.: Digitalizácia v továrni. Žilinská univerzita v Žiline, Žilina 2020. 
3. iQservices, s.r.o, Reverzný Inžiniering:

http://www.iqservices.eu/sk/sluzby/reverzny-inziniering.html, 25.10.2021

4. GREGOR M., MEDVECKÝ Š., ŠTEFÁNIK A.: 3D digitalizácia a modelovanie vel'kých objektov. In: ProIN. 2017. ISSN 1339-2271.

5. BERLIN R.: Accurate robot and workcell simulation based on 3D laser scanning. Proceedings of the 333rd ISR (International Symposium on Robotics) October 7 - 11, 2002, [online]. In: https://research.chalmers.se/en/publication/100318. 25.101.2021

6. GREGOR M., MEDVECKÝ Š., ŠTEFÁNIK A., FURMANN R., MAČUŠ P.: 3D laserové skenovanie vel'kých objektov. 2016.

7. SÝKORA P.: MicroStation V8 XM EDITION. 2007.

8. SÝKORA P.: MicroStation V8, podrobná príručka. 2001. 